\title{
Analysis of Fire Data in Oman
}

\author{
K.S. Al-Jabri, A.W. Hago, A.S. Alnuaimi and S. Al-Mahrooqi
}

Department of Civil and Architectural Engineering, College of Engineering, Sultan

Qaboos University, P.O.Box 33, Al Khod 123, Muscat, Sultanate of Oman,

Email: aljabri@squ.edu.om.
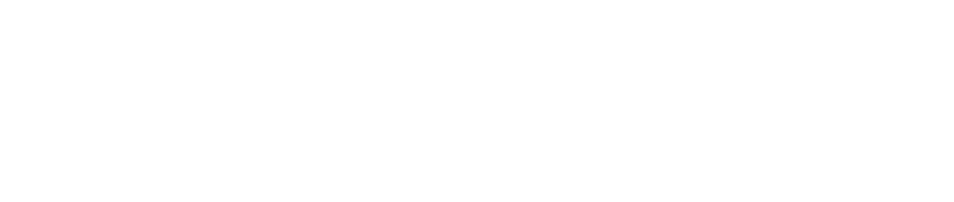

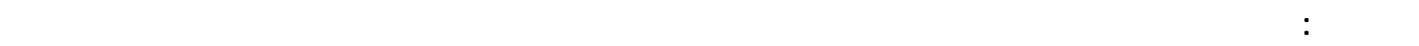

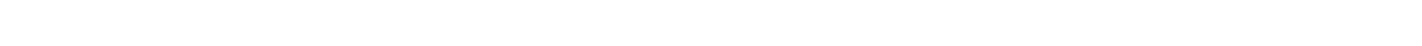

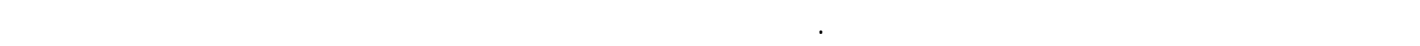

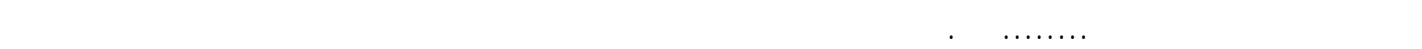

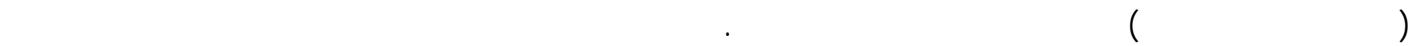

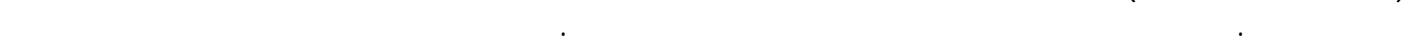

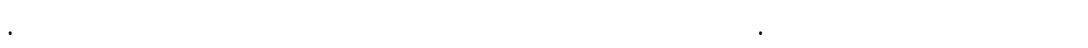

\begin{abstract}
The aim of this study is to illustrate the problem of fire accidents in the Sultanate of Oman and their causes in order to find out how the existing data could be used as a base to improve fire resistance, to detect the weak points (vulnerability to fire) in existing structures, and to minimize fire occurrences in places where it is high. This will also provide useful recommendations with regard to fire safety including causes, people's awareness and education, etc. Fire data in Oman were collected from two sources: The Directorate General of Civil Defence (Public Relations Department) and Sultan Qaboos University library. The collected data represent the number of fires in Oman during the last decade. It also includes fire distribution by type and averages. The analysis shows that there is a linear increase in the number of fire accidents in the last decade with time. Many factors are included as potential sources, which are explained in the paper, and suggestions are made for possible control.
\end{abstract}

KEYWORDS: Analysis, Fire safety, Dwelling, Farms, Fatality, Financial loss, Fire.

\section{Introduction}

Since the discovery of fire, mankind has realized its power and is still searching for sensible

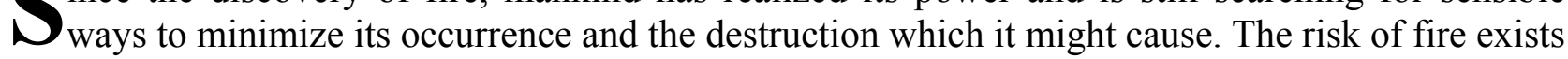
in every building and it is accepted that absolute safety from fire is impossible. Over the centuries fire safety regulations have been introduced in many countries with two main objectives:

- To reduce the loss of life and ensure the safety of the occupants and those in the neighboring buildings.

- To minimize the financial losses both in the property and its neighbourhood, medical costs, interruption to business, etc.

Active and passive fire prevention measures have been implemented in many countries to prevent fire occurrence. Regulations insist that such measures must strictly be followed in order to minimize the risk of fire. This can be achieved either by early detection of fire or by allowing ample time for safe evacuation of occupants and for the fire brigade to fight the fire safely. However these measures cannot provide complete immunity against the risk of fire. 
Analyzing existing fire accident data and identifying the causes of fire accidents is of great importance in improving fire resistance techniques and methods. Also this can help in detecting the weak points in fire safety regulations and thereby help in developing strategies for minimizing fire occurrences particularly in places where they are high. This, in turn, will provide better understanding of fire safety including causes, people's awareness and education.

This paper presents an analysis of fire accidents in the Sultanate of Oman during the past eleven years (1990-2000). The major fire types studied in this paper are: dwelling fires, farm fires and vehicle and equipment fires, while other minor fire types are referred to as "other fires". Financial losses in Rial Omani (R.O.), saved properties and the number of deaths and injuries caused by fire are the essential elements of fire data collected. Because of the random nature of its occurrence (i.e. fire does not happen in the same pattern and in the same manner unless through arson), the average number of occurrences per month is reported and fire causes are discussed, and some solution measures are proposed.

\section{Fire Safety Regulations in the Sultanate of Oman}

The Sultanate of Oman is located in the south east corner of the Arabian Peninsula and has an estimated population of 2 million and an area of $309,000 \mathrm{~km}^{2}$. In the last three decades and due to the discovery of oil, Oman has witnessed considerable and rapid development in all aspects of life. This was accompanied by an increase in the number of dwellings and commercial and industrial buildings in different regions. The number of vehicles and road users has also increased significantly.

Fire accidents in Oman are not as high as in many other countries. This is due to less congestion in towns, and the use of non-combustible construction materials. Yet people do not have enough knowledge concerning fire safety. Fire statistics (Annual reports, 1990-2000) within the Sultanate of Oman reveal that in the last decade there were over 17500 fire accidents and nearly 750 deaths and injuries caused by fire. Beside loss of life, there is an estimated cost of nearly R.O. 100 million for damage to property.

Fire safety regulations in the Sultanate of Oman are set up by the Directorate General of Civil Defense. These regulations are implemented by the different organizations throughout the country. From fire safety perspective, the Civil Defense has the following objectives:

- Reducing the risk of fire in buildings and other premises as well as in petrol and service stations.

- Reducing the risk of fire when transporting, handling and storing hazardous materials.

- Increasing fire safety awareness among the public through seminars, exhibitions, public media and visits to schools to explain the fire safety regulations, fire prevention measures and precautions to be taken in the event of fire.

- Preparing and issuing fire safety code of practice in collaboration with Directorate General of Standards and Measurements as a national health and safety code of practice in the country.

Each organization has the freedom to prepare and implement its own fire safety policy in accordance with the national health and safety code of practice. However, a regular inspection is carried out by Civil Defense inspection teams to residential, commercial and industrial premises to ensure compliance with fire safety regulations. Also, approval from the Civil Defense authority must be obtained prior to the commencement of the construction of any building, especially multistorey residential and commercial buildings and industrial premises.

\section{Recorded Fires in Oman}

The total number of fires from 1990 to 2000 is shown in Figure 1. It can be seen that the total average number of fires per year reached almost 1068. The number of fires was 903 and 927 in 


\section{ANALYSIS OF FIRE DATA IN OMAN}

1990 and 1991, respectively. The number of fires increased slightly until 1995 and declined by $11 \%$ in 1996. However, in 1998 the number of fires recorded reached 1251 fires,

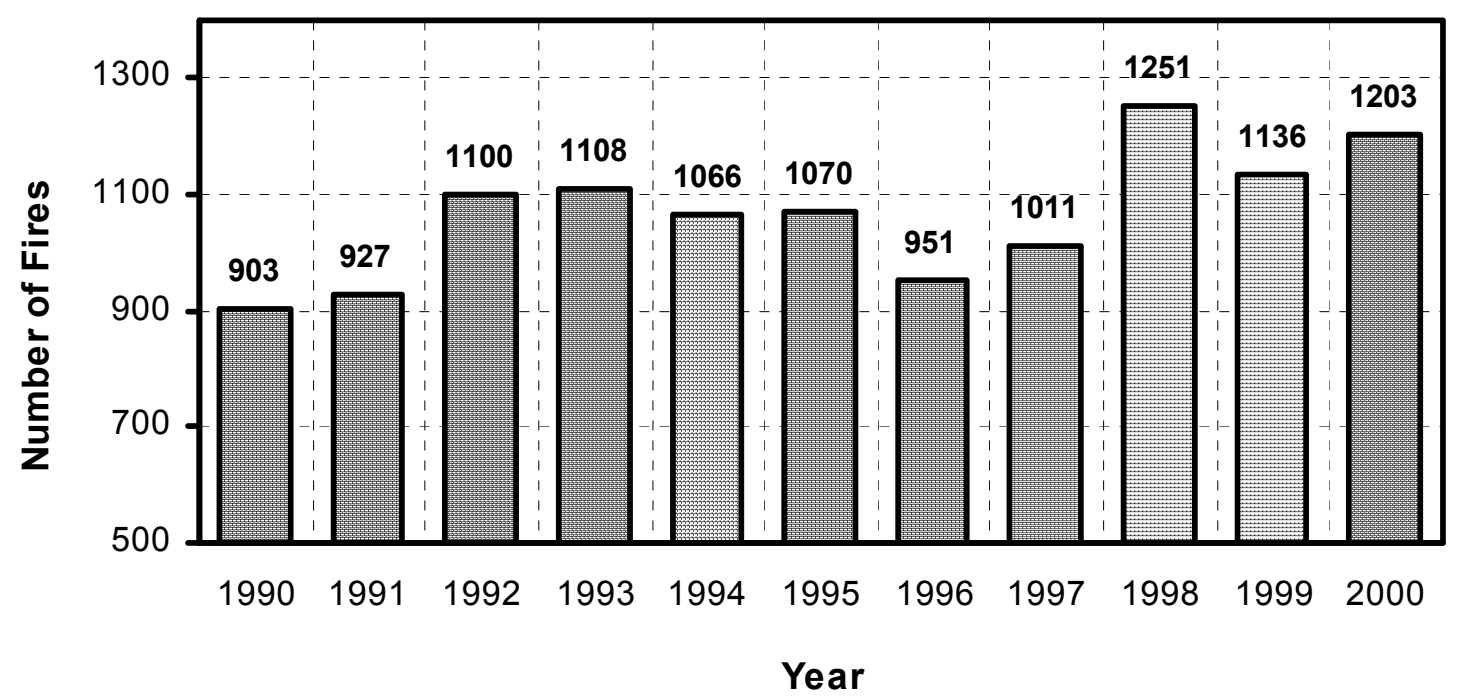

Figure 1. Recorded fire accidents in Oman.

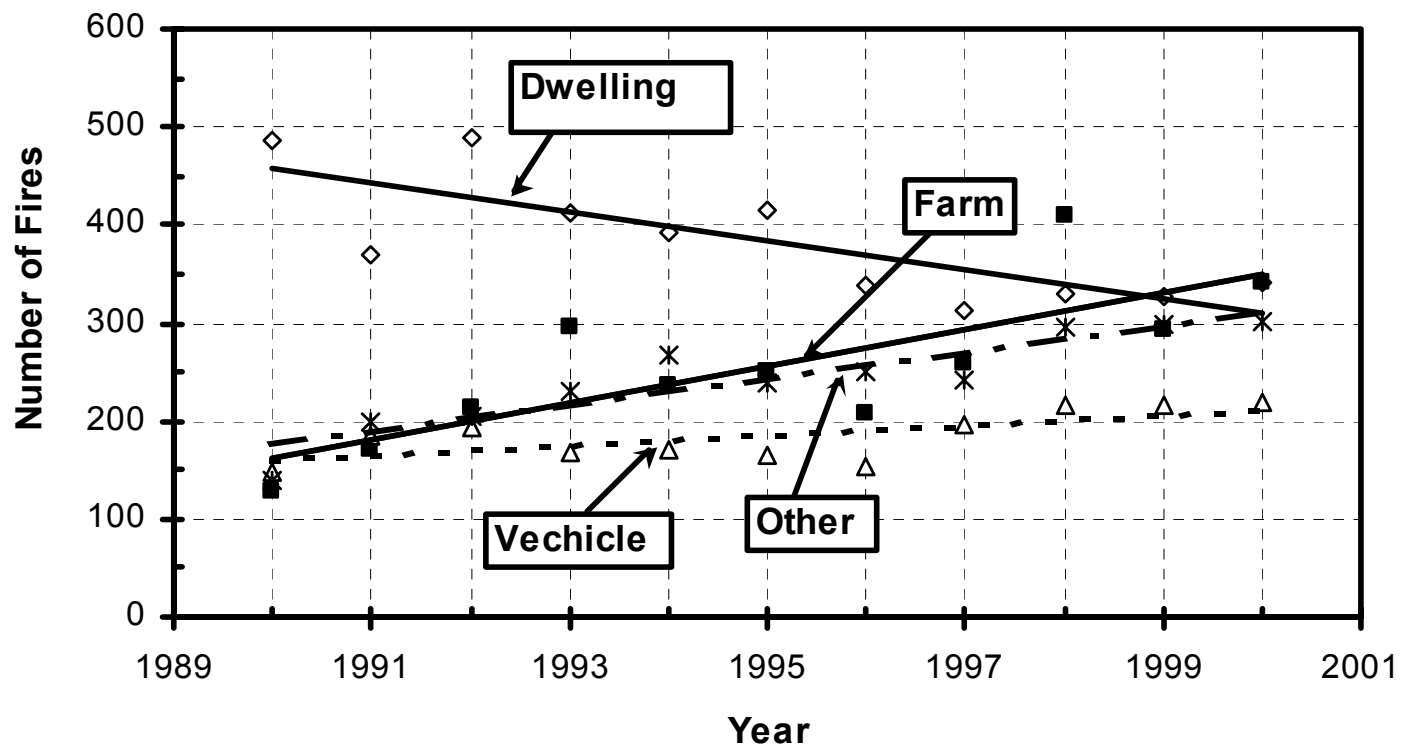

Figure 2. The number of fire types in Oman.

which is $27.8 \%$ more than in 1990 and the highest ever recorded. In 1999, the number of fires decreased by $9.2 \%$ comparatively, whereas in 2000 it dropped by only $3.8 \%$. It may be seen from Figure 1 that the total number of fires at the end of the decade is to some extent more than those at the beginning. This increase in the number of fires may be attributed to the increase in the number of residential, commercial and industrial buildings. This is depicted in Table 1, which shows the number of building permits in the Muscat region during the last decade (Department of building permits, 2000). A breakdown of the different types of fires is shown in Figure 2 and will be discussed in the following sections.

\section{Dwelling Fires}

During the last decade there was a general decrease in dwelling fires as can be seen in Figure 2. The percentage of dwelling fires in the year 2000 was $28.3 \%$ of the total number of fires in that 
year, compared to $53.9 \%$ in 1999 , indicating a drop of $25.6 \%$. Although the general trend during the 1990-2000 period was a decrease in fires, some minor variations were observed. The highest number of dwelling fires occurred in 1992 with 490 fires and the lowest was in 1997 with 314 fires. The decline in dwelling fires may be attributed to many reasons. The most likely reason may be the increase in the public educational level during the last decade. It is well known that education plays an important role in reducing the risk of fire by increasing public awareness of fire safety. The second reason is probably due to the Directorate General of Civil Defense playing a major role in increasing public awareness of the risk of fire among the public, school children and government sectors through lectures, seminars, TV programs and fire safety exhibitions.

Table 1: Number of Building Permits in Muscat Region (Excluding Industrial Buildings).

\begin{tabular}{|c|c|}
\hline Year & Number of building permits \\
\hline 1991 & 1940 \\
\hline 1992 & 2263 \\
\hline 1993 & 2079 \\
\hline 1994 & 2126 \\
\hline 1995 & 1865 \\
\hline 1996 & 1700 \\
\hline 1997 & 1905 \\
\hline 1998 & 1951 \\
\hline 1999 & 1552 \\
\hline 2000 & 1475 \\
\hline Total & $\mathbf{1 8 8 5 6}$ \\
\hline
\end{tabular}

\section{Farm Fires}

As can be seen in Figure 2, there was a gradual increase in farm fires. In 1990 the number was 129 fires, which contributed to $14.3 \%$ of the total number of fires. In 1991 and 1992, this number had doubled. The highest number of farm fires was recorded in 1998, when there were 410 fires. This gradual increase in the number of farm fires, despite developments in farming methods and waste disposal techniques, may be due to the lack of awareness among farmers and workers. Based on Civil Defense information, many farmers still burn the dry waste from farms near trees and other grasses which has the effect of increasing the possibility of fire. Many farmers are careless when they burn farm waste particularly in windy weather. Also, the majority of farmers are still hiring unskilled cheap labor, many of whom are illiterate and lack the basic knowledge regarding fire safety in farms. In addition, many of these laborers are smokers, which in turn increases the possibility of fire. Moreover, leaving dry grasses in the sun makes them vulnerable to fire. Observations show that many farm fires occur in summer when the temperature is very high, reaching above $50{ }^{\circ} \mathrm{C}$. For these reasons, farmers are still lacking in awareness with respect to fire safety in farms. This matter needs to be addressed seriously by the fire safety authorities.

\section{Vehicle and Equipment Fires}

The number of vehicle and equipment fires is also shown in Figure 2. Like farm fires, there is also a gradual increase in the number of vehicle and equipment fires. The lowest number of fires recorded was 147 in 1990, while the highest was 218 in the year 2000 . The increase may be attributed to the following reasons:

- Negligence: Many drivers and passengers do not dispose of cigarettes properly in cars.

- Arson for revenge or compensation.

- Lack of regular maintenance particularly in summer, which increases the risk of electrical faults. 
- The majority of drivers do not keep fire extinguishers in their cars and even if they do many of them do not know how to use them properly.

\section{Other Fires}

Other fires are defined as fires which occur in companies, garages and workshops. From Figure 2 the lowest number of such fires was 140 in 1991 which increased to 302 in the year 2000, showing a substantial increase. This is probably due to the fact that many of the companies and factories are not complying with fire safety regulations, which has an influence on increasing the risk of fires in these places. The other reason is that in the last ten years the number of industrial regions has increased quite rapidly and consequently the chances of fire risk have also increased.

\section{Average Number of Fire Distribution by Type}

The distribution of percentages of fire types is shown in Figure 3. It may be seen that although there was a reasonable decrease in the number of dwelling fires since 1990, it still represents the highest percentage (36\%) in comparison with other fire types. This is due to the increase in the number of residential, commercial and industrial buildings which was constructed in the last ten years. From Table 1 it may be seen that the total number of building permits (excluding industrial buildings) issued by Muscat municipality in the Muscat area was 18856 (Department of Building Permits). The farm, vehicle and equipment and other fires contributed, respectively, to $24 \%, 22.7 \%$ and $17.3 \%$ of the total average percentage.

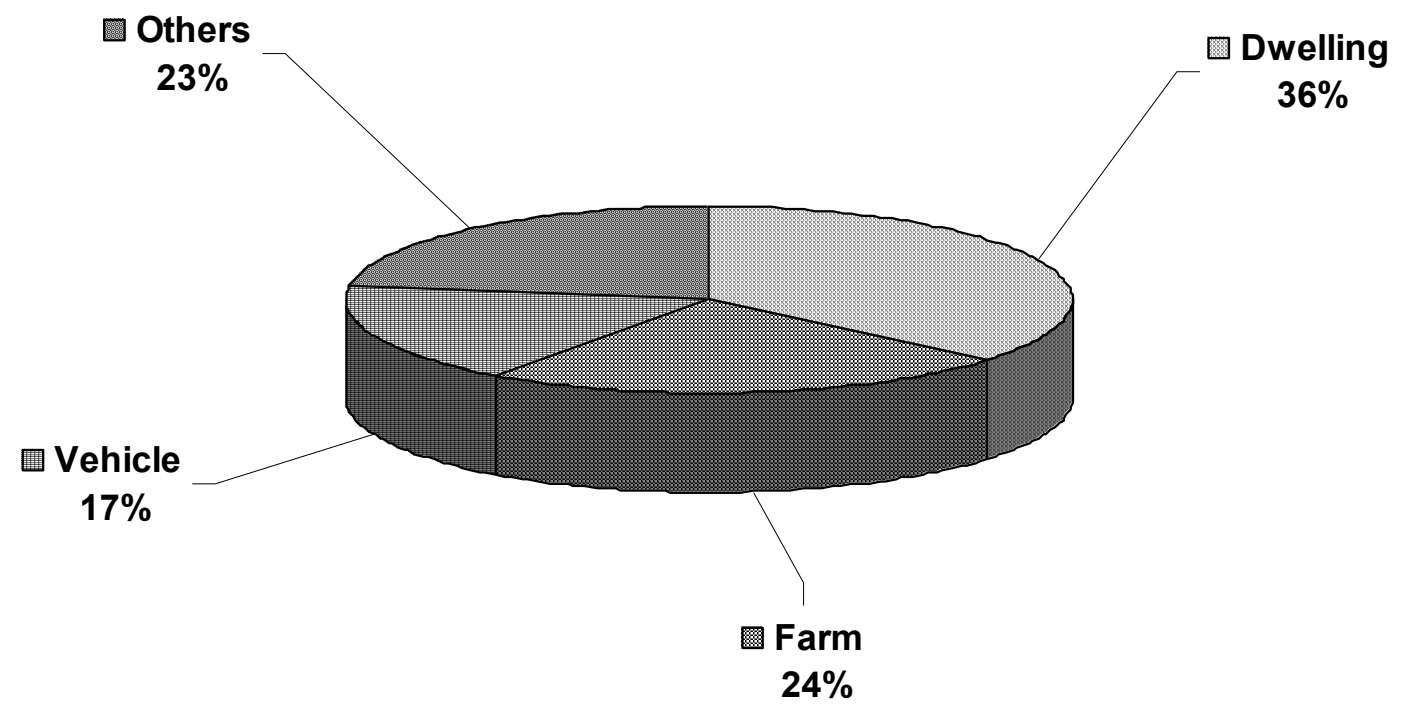

Figure 3. The average number of fire types in Oman (1990-2000).

\section{Financial losses}

This section concentrates primarily on the financial losses in the properties and premises. The estimated total financial losses in fire accidents in Oman in the last decade were R.O. 57.4 million. As can be seen in Figure 4, the lowest losses have been recorded during the period from 1990 to 1998. For instance, in 1990 the financial losses reported was R.O 0.798 million. In 1995 the financial losses were R.O. 1.903 million. After that, it dropped significantly to R.O 0.629 million in 1997. However, in 1999 and 2000 financial losses increased considerably. The financial losses were estimated at R.O. 22.6 and 25.4 million for 1999 and 2000, respectively. This increase is due to fire accidents in large factories. It is clear that the increased number of industrial regions has contributed significantly to the increased value of financial losses. 
Therefore, in an industrial region, factories should comply very strictly with the fire safety rules and fire fighting units should be made available in the vicinity of industrial estates.

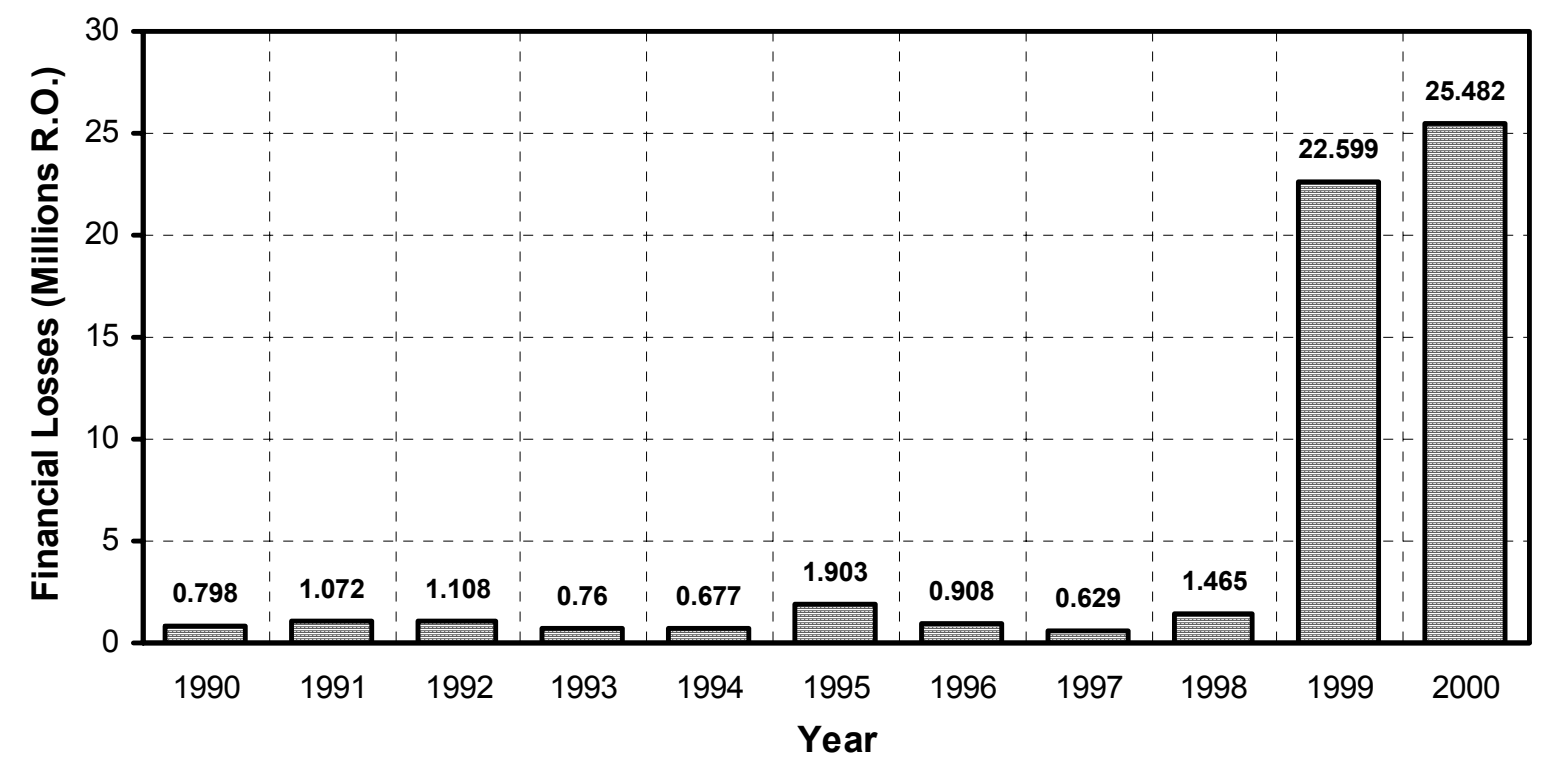

Figure 4. Financial losses due to fire (in million R.O.).

\section{Saved Properties}

Figure 5 shows the value of saved property (in millions R.O.) in the last ten years. The total value of property, which has been saved by the Civil Defense was estimated at R.O. 281.906 million, with $43.3 \%$ of the total property saved in 1990 and 1991 . This means that almost more than two thirds of the total saved property happened in these two years. Then it decreased considerably between 1993 and 2000, despite the increase observed in the saved properties in 1995 and 1999.

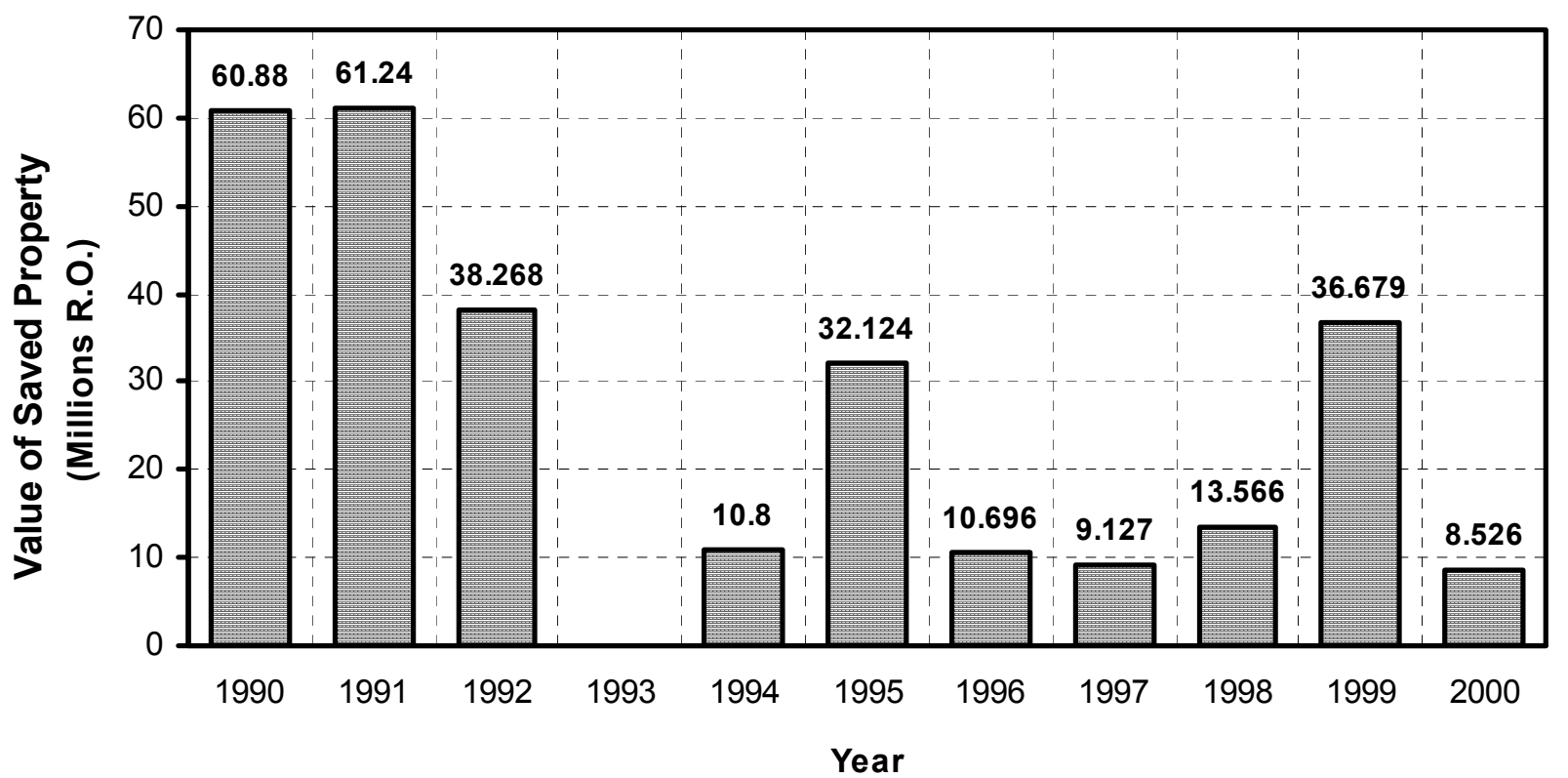

Figure 5. The value of saved property due to fire (in million R.O.). 


\section{ANALYSIS OF FIRE DATA IN OMAN}

\section{Fire Causalities}

Figures 6 and 7 show that the total number of deaths in the last 11 years was 167 and the number of the injuries was 563, which is more than three times the number of deaths. The lowest number of deaths and injuries per year was recorded in 1990 as 4 and 32, respectively. However, the largest number of deaths was recorded in 1993 and 1994, and the largest number of injuries was in 1994 and 2000. One of the main causes was the inhalation of smoke, particularly carbon monoxide. Moreover, many deaths and injuries could have been prevented if people had had early warning and had been able to escape quickly. It has been observed that the shorter the time interval between the start and discovery of the fire, the lower the death or the injury rate is.

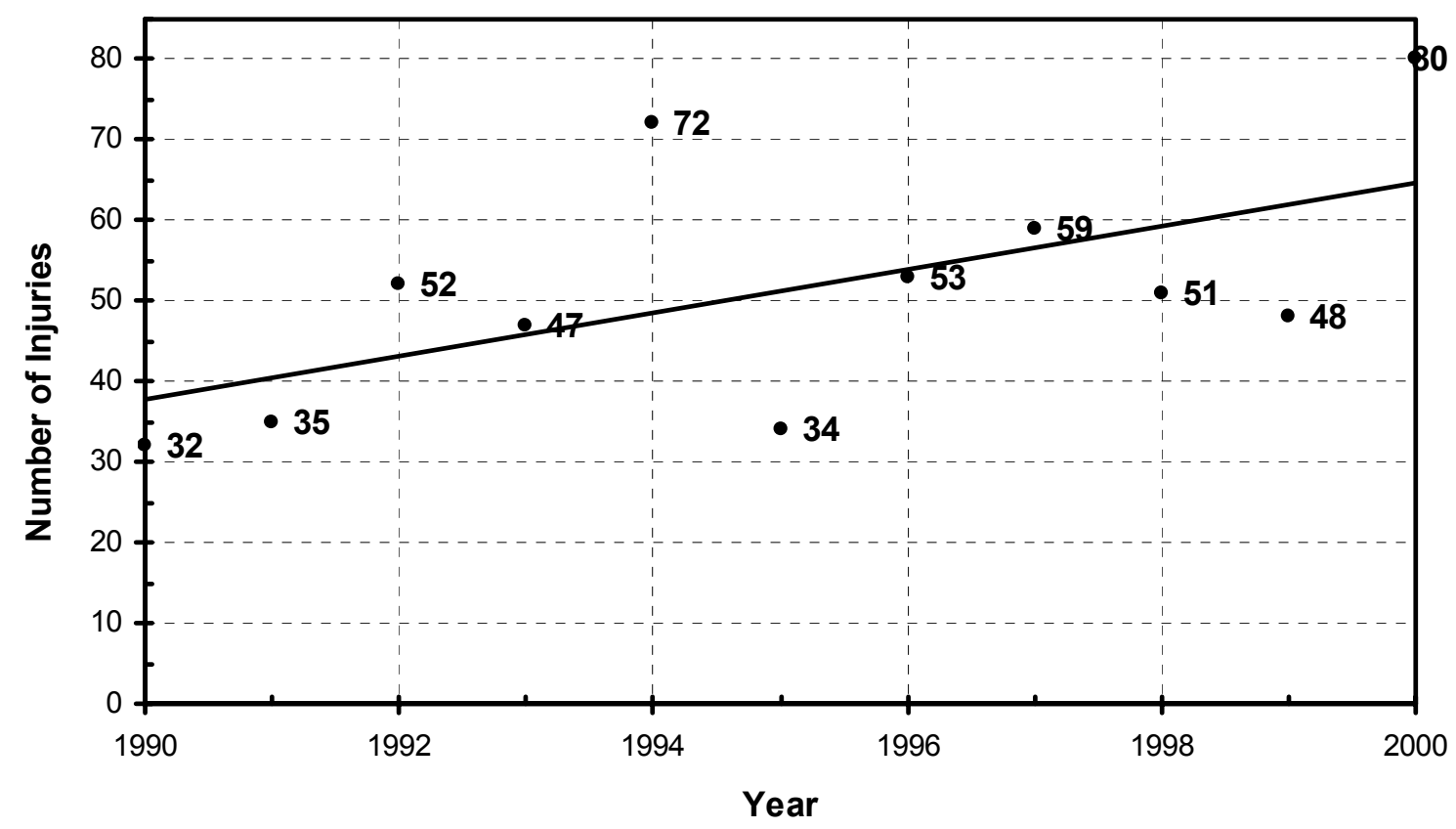

Figure 6. The number of injuries due to fire.

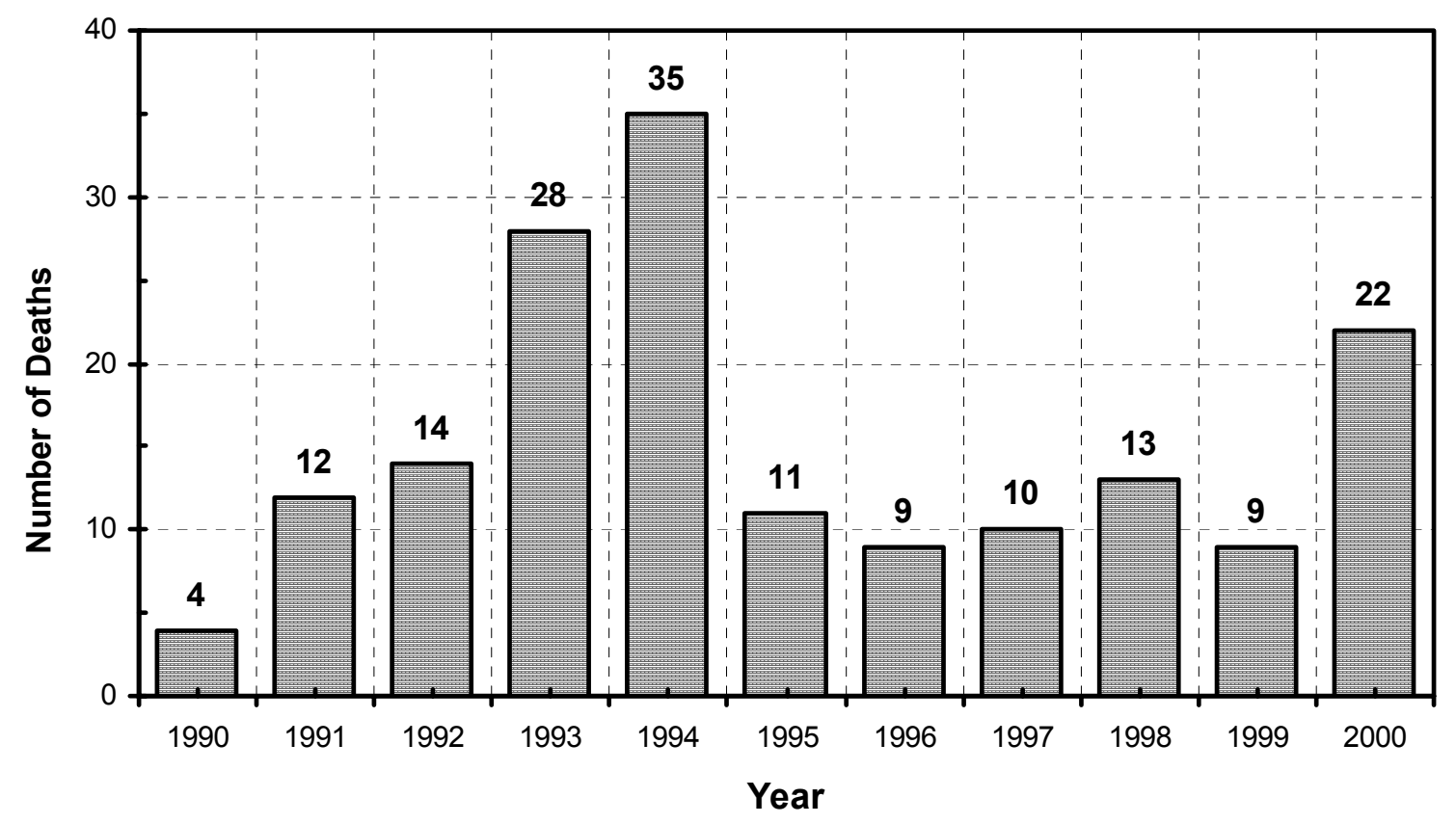

Figure 7. The number of deaths due to fire. 


\section{Monthly Fires}

The average monthly fires during the last decade are presented in Figure 8 . The lowest percentage of fires was between November and January (during winter) while the highest was in April, May and June (summer season). The highest percentage recorded was in May, which accounted for about $12 \%$ of the overall average. However, the lowest number of fire accidents was in November which is estimated to be $7 \%$ of the total average. It should be noted that the months of May to July are usually the hottest months of the year in the Sultanate of Oman.

The rise in fire accidents during summer may be due to the following reasons:

1. Electrical supply is overloaded due to the excessive use of air conditioning. This causes electrical faults which in turn increase the risk of fire.

2. Irregular maintenance of cars may also lead to a higher risk of fire.

3. The fierce heat from the sun and the lack of rain during the summer may lead to fires in dry grassland.

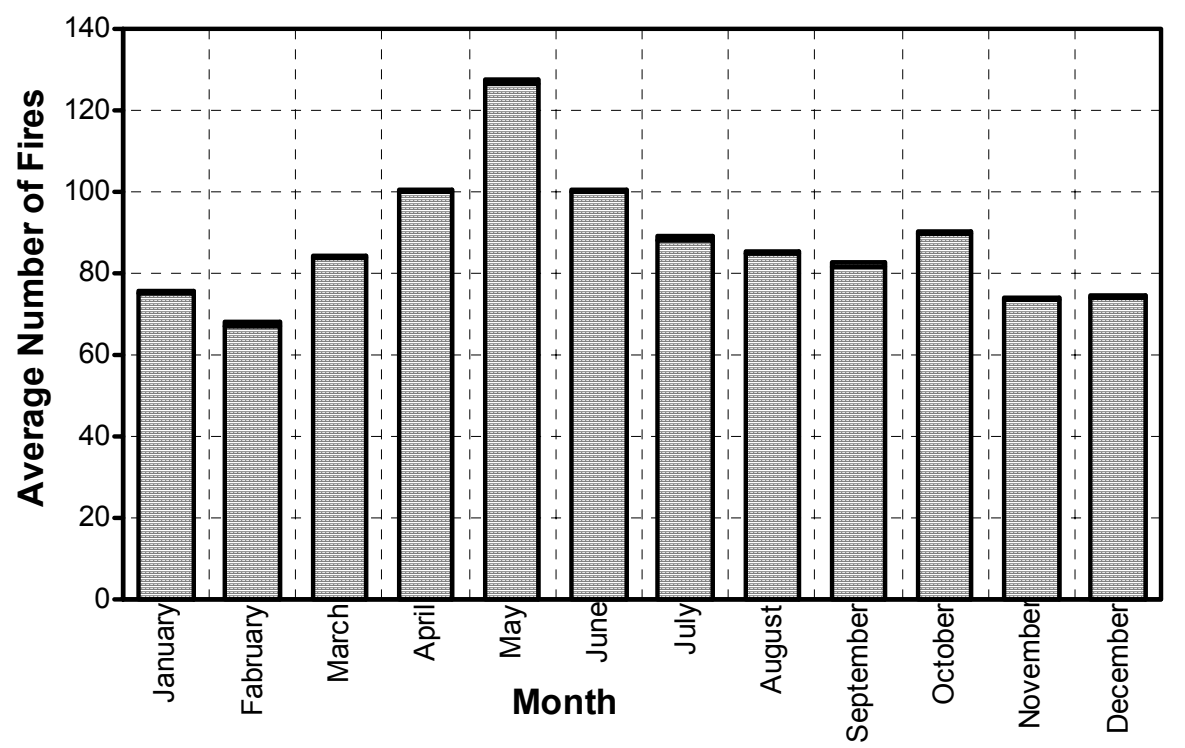

Figure 8. The average number of monthly fires (exc. 93).

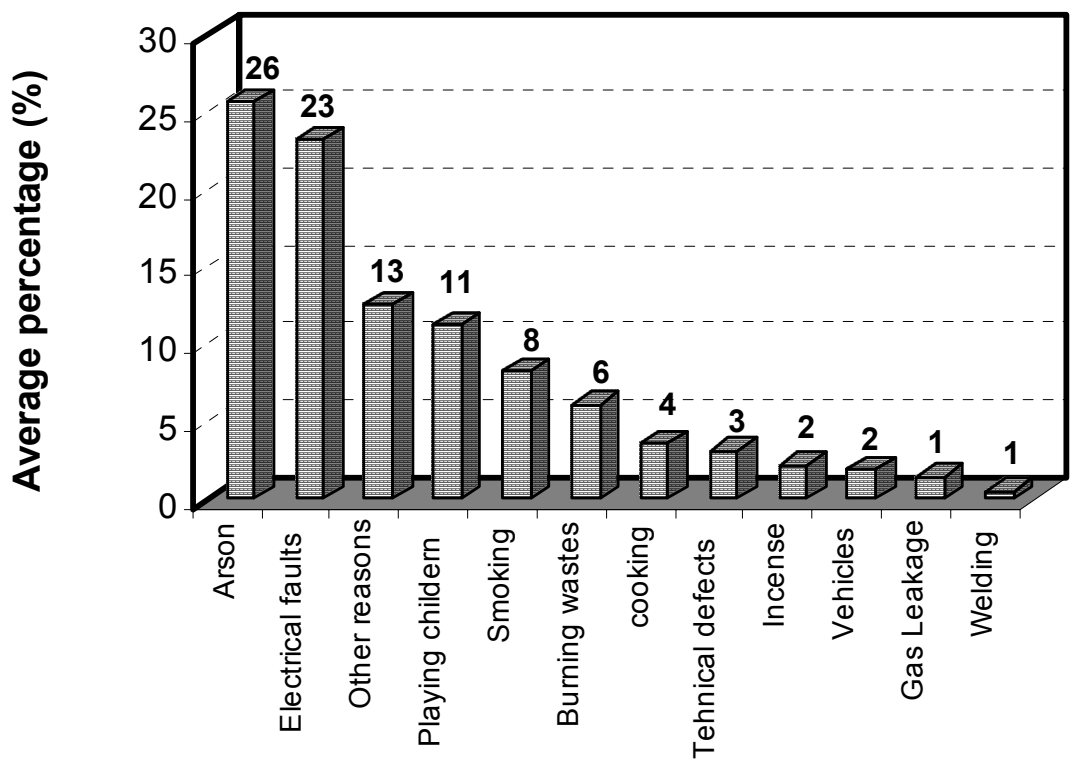

Figure 9. The main fire causes in Oman. 


\section{ANALYSIS OF FIRE DATA IN OMAN}

\section{Average Number of Fire Causes in Oman}

It can be seen from Figure 9 that according to the data of the Directorate General of Civil Defense arson is the main cause of fire in Oman, contributing to $26 \%$ fires. Electrical faults come in second place by $23 \%$ of the total percentage. The percentage of fires caused by children playing was evaluated by $11 \%$ of the whole percentage. Estimates of the percentage of fires caused by smoking and burning waste were about $8 \%$ and $6 \%$, respectively.

\section{Conclusions}

Analysis of fire data collected in Oman from 1990 to 2000 is very important in helping to minimize fire occurrence. From the results obtained the following conclusions were drawn:

a) The increase in the total number of fires in Oman may be attributed to the increase in the population and the increase in the number of residential, commercial and industrial buildings. This increase is not matched by a corresponding compliance with safety regulations.

b) Although there has been a gradual decrease in dwelling fires during the last decade, they still record the highest percentages followed by farm fires.

c) The gradual increase in the number of farm fires, despite developments in farming methods and waste disposal techniques, may be due to the lack of awareness among farmers and workers, which needs to be considered seriously by the fire safety authorities.

d) The gradual increase in vehicle and equipment fires may be attributed to negligence, arson and lack of regular maintenance.

e) The number of fires in factories and workshops has increased owing to the fact that many companies and factories are not maintaining a strict enough observance of fire safety regulations.

f) Financial losses have increased quite considerably owing to the increase in the number of industrial areas, which is not matched by corresponding compliance with safety regulations.

g) The main causes of deaths were linked to smoke inhalation.

h) The highest number of fires was recorded in the summer between April and July because of the overloading of the electrical supply and dry leaves and grasses catching fire in the hot dry weather.

i) According to Civil Defense statistics the main causes of fires in Oman are arson and electrical faults.

\section{Recommendations}

In order to minimize the risk of fire accidents in buildings, the following points may be considered as recommendations based on the study made in this paper:

a) Use of fire retarding materials in the construction of buildings, warehouses, workshops, etc.

b) Proper disposal of farm and industrial wastes.

c) Annual inspection of buildings and vehicles to ensure compliance with safety regulations.

d) Establishment of fire safety management policy throughout the country.

e) Increase in the use of the media for public awareness to fire safety.

f) Increase in the awareness of children of fire safety at home, school and in the community.

g) Strict implementation of fire safety regulations in all factories and workshops.

h) Proper installation of fire fighting systems in labour accommodation barracks, especially those built from combustible materials.

\section{Acknowledgement}

The authors would like to thank the Directorate General of Civil Defense for providing the data for this research. Thanks are also extended to Muscat Municipality for providing some of the data needed in the research. 
K.S. AL-JABRI, A.W. HAGO, A.S. ALNUAIMI and S. AL-MAHROOQI

\section{References}

The Annual Reports from 1990 to 2000, General Directorate of Civil Defense, Royal Oman Police, Sultanate of Oman.

Department of Building Permits, General Directorate of Technical Affairs, Muscat Municipality, Sultanate of Oman, 2000.

Received 6 November 2001

Accepted 2 December 2003 